\title{
The Use of Obsidian for K-Ar Dating
}

\author{
ICHIRO KANEOKA * \\ (Received 28 December 1968;
}

\begin{abstract}
The argon retention of obsidian was studied with respect to the degree of hydration. It is found that there is a negative correlation between them. Consequently, for $\mathrm{K}$-Ar dating, it is recommended to use obsidians whose $\mathrm{H}_{2} \mathrm{O}(+)$ contents are small, say, below about $0.5 \%$ of weight. It is also found that a rhyolite sample shows poorer argon retentivity than that of a fresh obsidian. The probable age of obsidian at Wada Toge (pass) is about $0.9-1.1 \mathrm{~m} . \mathrm{y} .$.
\end{abstract}

\section{Introduction}

Recent development in $\mathrm{K}$-Ar dating method now enables us to determine the age of some volcanic rocks as young as several thousand years. ${ }^{1,2)}$ For this, however, potassium rich minerals such as sanidine must be used. In K-Ar dating, the possibility of dating of young samples is primarily limited by the accuracy in the determination of radiogenic argon40. The amount of radiogenic argon-40 is expressed as follows.

$$
\left({ }^{40} \mathrm{Ar}\right)^{*}=\left({ }^{40} \mathrm{~K}\right)\left(\mathrm{e}^{\lambda \mathrm{t}}-1\right)
$$

where

$\left({ }^{80} \mathrm{Ar}\right)^{*}$ : the amount of radiogenic argon-40 at present

$\left({ }^{\circ} \mathrm{K}\right)$ : the amount of potassium-40 in the sample at present

$\lambda$ : total decay constant of potassium- 40

$t$ : time since radiogenic argon -40 was accumulated in the sample

In the determination of radiogenic argon analysis, the correction for the atmospheric argon contamination can be made by measuring argon- 36 , as the isotopic ratio of ${ }^{40} \mathrm{Ar} /{ }^{36} \mathrm{Ar}$ of the atmos. pheric argon is constant $\left({ }^{40} \mathrm{Ar} /{ }^{36} \mathrm{Ar}=\right.$ 295.6). The effect of atmospheric argon contamination in the determination of radiogenic argon is expressed as

$$
E=\frac{f}{1-\mathbf{f}}(\mathbf{e})
$$

3), where

E: error in the determination of radiogenic argon- 40

$f:$ atmospheric contamination

$$
\left(=\frac{\left({ }^{40} \mathrm{Ar}\right) \text { air }}{\left({ }^{40} \mathrm{Ar}\right) \text { total }}\right)
$$

e : error in the measurement of the isotopic ratio $\left({ }^{40} \mathrm{Ar}\right) /\left({ }^{36} \mathrm{Ar}\right)$

Considering that mass spectrometric isotopic determination of ${ }^{40} \mathrm{Ar} /{ }^{36} \mathrm{Ar}$ can be made with a precision of $\pm 1 \%$, which is a general case in the present analysis, if ${ }^{40} \mathrm{Ar}$ is to be measured within a certain percentage of error, say within $\pm 10 \%$, Eq. 2 shows that the atmospheric argon contamination must be lower than 0.9. As the percentage of

* Geophysical Institute, Faculty of Science, University of Tokyo,11-16, Yayoi 2-chome, Bunkyo-ku, Tokyo 
atmospheric argon contamination is primarily depend on the total amount of radiogenic argon-40 which is in turn determined by the potassium content and the age, the final sensitivity of the ${ }^{40} \mathrm{Ar} \mathrm{de}$ terminations can be expressed in terms of the amount of potassium and the age. This is shown in Fig. 1. Therefore in order to date young samples, it is necessary to use such samples rich in potassium content as much as possible.。Further it is also important that the sample should have the high argon retentivity. Sanidines satisfy these conditions and they are regarded as very good samples for $\mathrm{K}$-Ar dating.

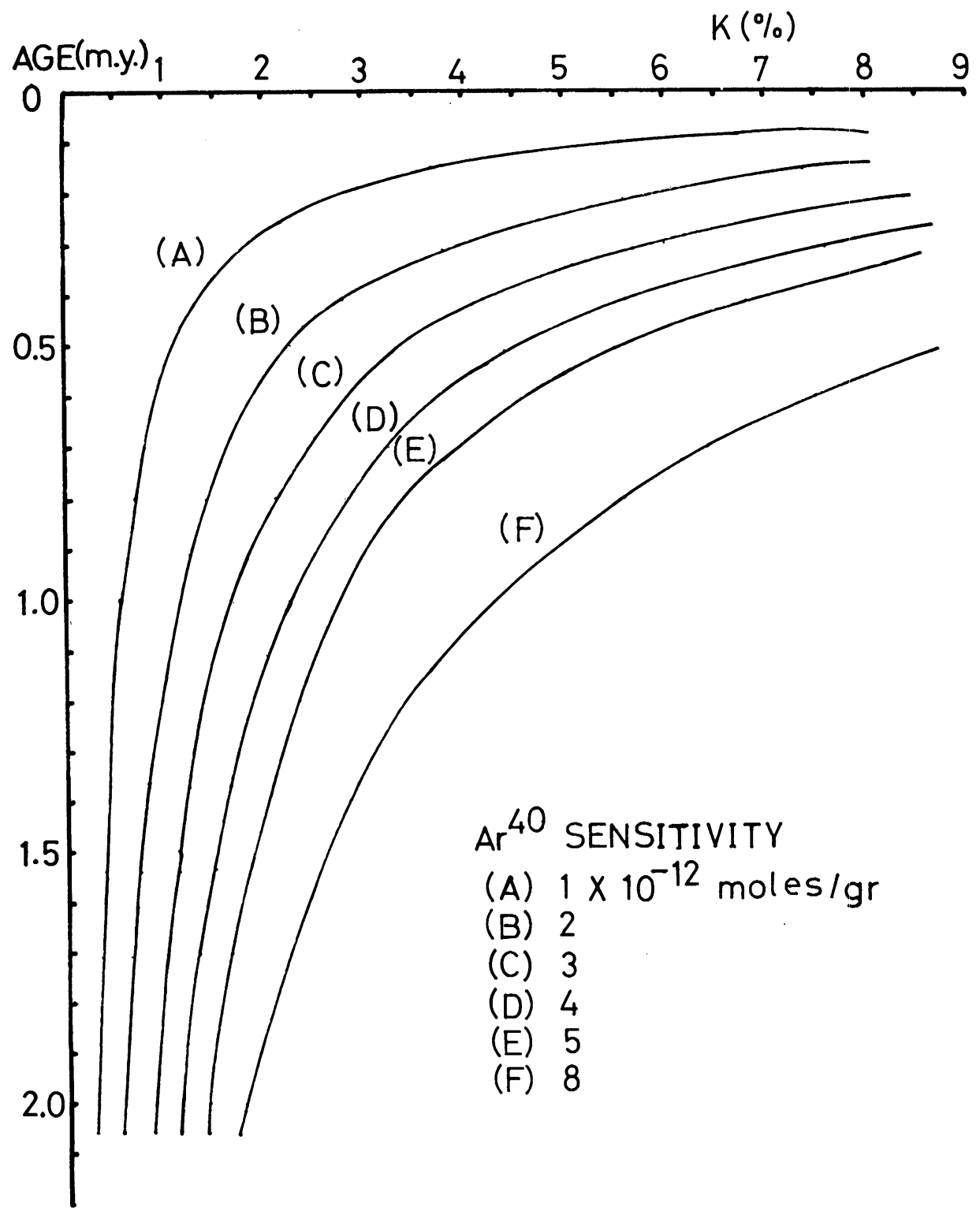

Fig. 1. The relationship between the measurable K-Ar age and the potassium content of the sample. The ${ }^{40} \mathrm{Ar}$ sensitivity is taken as a parameter. 
Because of scantiness of sanidine in Japan, it is imperative to find other suitable potassium rich minerals or rocks for K-Ar dating of young rocks. Rhyolite, dacite, obsidian, volcanic glass have high potassium content. Among these rocks, obsidian is particulary interesting for the following reasons.

1) Fission track dating method is also available for obsidian. Hence, the cross check for the measured ages can be made.

2) Obsidian seems to be relatively compact and seems to lose less radiogenic argon than other samples.

3) Obsidian can be used for palaeomagnetism, as obsidian has natural remanet magnetization. ${ }^{4)}$

However before using obsidian for $\mathrm{K}$-Ar dating, the following points should carefully be examined.

1) As obsidian is rather susceptible to weathering, such as hydration, it is important to study the relation between the argon retentivity and the hydration,

2) As obsidian is supposed to cool very rapidly, primary argon may not have been fully degassed from the lava.

In this study, only the former case was studied.

\section{Samples and Sampling Locality}

Obsidians and rhyolites used in this study were collected from an obsidian mine at Wada Toge (pass). Hence, the samples should have the same age. Geological settings of Wada Toge (pass) are described by Y. Kawano. ${ }^{5)}$

Several kinds of obsidians were selected to study the relation between the argon retentivity and the degree of the hydration. Obsidian A and B (Table. 1) seems to be comparatively fresh. However obsidian $\mathrm{C}$ is the light-gray one. Obsidian $\mathrm{D}$ is the mixture of black obsidians and light-gray perlites. For comparison, rhyplite $\mathrm{E}$ is also studied. The rhyolite is fresh both macroscopically and microscopically. Microscopic observation shows that these obsidians are completely glassy.

\section{Experimental Procedures}

\section{1 Argon Analysis}

A small pieces of obsidian of about $5 \sim 10$ grammes is used for argon extraction, in which the sample is put in a Mo crucible (diameter $=2 \mathrm{~cm}$, height $=5$ $\mathrm{cm})$. For rhyolite, however, about 10 grammes of crushed samples (mesh size $=100$ ) is used.

Mo crucible is degassed previously at about $1400^{\circ} \mathrm{C}$ for about 30 minutes. The vacuum of extraction system is about $5 \times 10^{-5} \mathrm{mmHg}$ with $\mathrm{Ti}$ furnace on and $5 \times 10^{-\epsilon} \mathrm{mmHg}$ with Ti furnace off. Samples are fused with a induction heater at about $1300^{\circ} \mathrm{C}$ for about 1 hour. The extracted gas is then purified with $\mathrm{CuO}$ at about $350^{\circ} \mathrm{C}$ and $\mathrm{Ti}$ at $900^{\circ} \mathrm{C}$ respectively.

Argon analysis is made with a 60 degree magnetic sector Reynolds type mass spectrometer with a radius of curvature of $15 \mathrm{~cm}^{6}{ }^{6)}$ The detection of ions is made with a vibrating reed electrometer with the input resistance of $10^{\mathrm{w}} \Omega$. The isotopic ratios of ${ }^{36} \mathrm{Ar} /{ }^{40} \mathrm{Ar}$ and ${ }^{38} \mathrm{Ar} /$ ${ }^{40} \mathrm{Ar}$ were determined by extrapolating the ratios to zero time when the sample was first admitted into the mass spectrometer. Mass discrimination was occasionally checked by analysing purified atmospheric argon. The ratio of ${ }^{36} \mathrm{Ar} /{ }^{40} \mathrm{Ar}$ is usually within $0.5 \%$ of the value given by Nier and no correction was made for ${ }^{40} \mathrm{Ar}$ determinations. 


\section{Kaneoka}

\section{2 Potassium and Sodium Analyses}

About 0.1 0.2 grammes of crushed samples of about 150 mesh were dissolved with $\mathrm{HF}$ and $\mathrm{HClO}_{4}$. The solution was evaporated to dryness. The precipitate was dissolved by $2.5 \mathrm{~N} \mathrm{HCl}$ and stored in a flask for analysis. Potassium was analysed by a flame photometer with $\mathrm{Li}$ internal standard and with $\mathrm{Na}$ buffer. Sodium was analysed by the flame photometer with $\mathrm{Li}$ internal standard. The analytical error of potassium is within $2 \%$, while that of sodium is almost $5 \%$ or more.

\section{3. $3 \mathrm{H}_{2} \mathrm{O}$ Analyses}

About $0.6 \sim 0.7$ grammes of crushed samples of about 150 mesh were put in a platinum crucible and weighted. Then it was put in a oven at $120^{\circ} \mathrm{C}$ for 1 hour, transferred into a desiccator and weighted. The decrease in the weight of the sample is considered to show the loss of water, which is indicated by $\mathrm{H}_{2} \mathrm{O}(-)$. Finally, it was transferred into an electric furnace and heated at $800-900^{\circ} \mathrm{C}$ for several hours. The decrease in the weight of the sample corresponds to $\mathrm{H}_{2} \mathrm{O}(+)$.

Although it is necessary to correct for the oxydation from $\mathrm{FeO}$ to $\mathrm{Fe}_{2} \mathrm{O}_{3}$, no correction is made for the effect of oxydation, as only the approximate value of $\mathrm{H}_{2} \mathrm{O}(+)$ is necessary for this discussion and the effect of the correction can be neglected.

\section{Experimental Results}

The results of $\mathrm{Ar}, \mathrm{K}, \mathrm{H}_{2} \mathrm{O}$ and $\mathrm{Na}$ analyses are tabulated in Table 1 . Argon

Table 1. The Analytical Results of Ar, K, Age, $\mathrm{H}_{2} \mathrm{O}(+), \mathrm{H}_{2} \mathrm{O}(-)$ and $\mathrm{Na}$

\begin{tabular}{|c|c|c|c|c|c|c|c|c|c|c|c|}
\hline Sample 1) & $\begin{array}{c}\text { Sample } \\
\text { W'eight } \\
\text { (gr) }\end{array}$ & $\begin{array}{c}\left({ }^{* A r}\right)^{*} \\
(\text { moles/gr) }\end{array}$ & 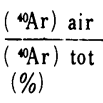 & $(\mathrm{K})(\%)$ & $\begin{array}{c}\left({ }^{4} \mathrm{~K}\right) \\
\text { (moles/gr) }\end{array}$ & $\frac{\left({ }^{\infty} \mathrm{Ar}\right)^{*}}{\left({ }^{*} \mathrm{~K}\right)}$ & \multicolumn{2}{|c|}{$\begin{array}{l}\text { Age }^{2)} \\
\text { (m.y.) }\end{array}$} & $\begin{array}{l}\mathrm{H}_{2} \mathrm{O}(+) \\
\text { (w.t. \%) }\end{array}$ & $\begin{array}{l}\mathrm{H}_{2} \mathrm{O}(-) \\
(\text { wt. \%) }\end{array}$ & $\begin{array}{c}\mathrm{Na} \\
(\%)\end{array}$ \\
\hline \multirow{2}{*}{ A } & 7.211 & $(3.507) \times 10^{-12}$ & 88.0 & \multirow{2}{*}{$3.97 \pm 0.03$} & \multirow{2}{*}{$1.207 \times 10^{-7}$} & $(2.905) \times 10^{-5}$ & $(0.50)$ & & \multirow{2}{*}{$1.05 \pm 0.02$} & \multirow{2}{*}{0.19} & \multirow{2}{*}{3.19} \\
\hline & 8.377 & 6.019 & 86.0 & & & 4.987 & 0.85 & & & & \\
\hline \multirow{2}{*}{ B } & 5.783 & 7.428 & 76.8 & \multirow{2}{*}{$3.97 \pm 0.02$} & \multirow{2}{*}{1.207} & 6.154 & 1.05 & \multirow{2}{*}{$\begin{array}{c}0.95 \\
\pm 0.10\end{array}$} & \multirow{2}{*}{$0.55 \pm 0.06$} & \multirow{2}{*}{0.23} & \multirow{2}{*}{3.28} \\
\hline & 7.314 & 5.984 & 88.4 & & & 4.958 & 0.85 & & & & \\
\hline \multirow{2}{*}{$\mathrm{C}$} & 10.422 & 4.677 & 73.8 & \multirow{2}{*}{$3.91 \pm 0.01$} & \multirow{2}{*}{1.189} & 3.934 & 0.67 & \multirow{2}{*}{$\begin{array}{c}0.71 \\
\pm 0.04\end{array}$} & \multirow{2}{*}{$1.94 \pm 0.07$} & \multirow{2}{*}{0.31} & \multirow{2}{*}{2.94} \\
\hline & 8.106 & 5.128 & 80.9 & & & 4.313 & 0.74 & & & & \\
\hline \multirow{2}{*}{ D } & 8.377 & 5.926 & 79.5 & \multirow{2}{*}{$3.93 \pm 0.01$} & \multirow{2}{*}{1.195} & 4.959 & 0.84 & \multirow{2}{*}{$\begin{array}{l}0.86 \\
\pm 0.02\end{array}$} & \multirow{2}{*}{$1.21 \pm 0.09$} & \multirow{2}{*}{0.44} & \multirow{2}{*}{2.76} \\
\hline & 6.122 & 6.119 & 89.2 & & & 5.120 & 0.87 & & & & \\
\hline \multirow{2}{*}{ E } & 13.275 & 5.579 & 55.8 & \multirow{2}{*}{$4.20 \pm 0.02$} & \multirow{2}{*}{1.277} & 4.369 & 0.75 & \multirow{2}{*}{$\begin{array}{c}0.74 \\
\pm 0.02\end{array}$} & \multirow{2}{*}{$0.59 \pm 0.02$} & \multirow{2}{*}{0.33} & \multirow{2}{*}{2.60} \\
\hline & 7.399 & 5.412 & 81.1 & & & 4.238 & 0.72 & & & & \\
\hline
\end{tabular}

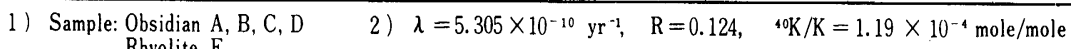
Rhyolite E

analysis was made in duplicate for each sample. It is shown in Table 1 that in general the relative error for the argon analysis is within $\pm 5 \%$ except for the obsidian A. A value of extracted argon for obsidian A is not so reliable, because the extraction was unsatisfactorily taken. Therefore the value is put in a paren. thesis. Potassium analyses were made with the standard deviation below $\pm 1 \%$. The result shows that potassium content is almost the same for each sample.

It can be seen that al though these samples should have the same age, the radiometric ages range from 0.67 to $1.05 \mathrm{~m} . \mathrm{y}$. . The difference in the ages 
among different samples is greater than that within the same sample. Therefore, the difference in the ages in the former case can not be attributed to experimental error. It is also remarkable that rhyolite sample shows comparatively younger age than those of obsidians.

$\mathrm{H}_{2} \mathrm{O}(+)$ analyses were made with the standard deviation below $\pm 10 \%$. As most of $\mathrm{H}_{2} \mathrm{O}(-)$ is regarded that they are adsorbed to the surface of the sample, only $\mathrm{H}_{2} \mathrm{O}(+)$ is important for the considerations of hydration. It is interesting that the amount of $\mathrm{H}_{2} \mathrm{O}(+)$ is larger for samples with younger experimental K-Ar ages. It is believed that a fresh obsidian has the amount of $\mathrm{H}_{2} \mathrm{O}(+)$ usually below $0.5 \%$. $^{7)}$ Among 4 samples analysed, only obsidian $B$ seems to be comparatively fresh. Obsidian $\mathrm{C}$ is most heavily hydrated. It is notable that the obsidian $\mathrm{A}$ and $\mathrm{B}$ have different amount of radiogenic argon and $\mathrm{H}_{2} \mathrm{O}(+)$ in spite of their similar appearances. Obsidian A and $B$ are also different in the sodium contents as shown in Table 1 . Sodium analyses show that these samples have different sodium concentrations, which seems to have some relations with the degree of hydration.

\section{Discussion}

It is reported that leaching of $\mathrm{Na}_{2} \mathrm{O}$ occurs during the hydration of volcanic glasses. ${ }^{8), 9)}$ There is observed, however, no correlation between the content of $\mathrm{K}_{2} \mathrm{O}$ and the content of $\mathrm{H}_{2} \mathrm{O}(+)$ for volcanic glasses. ${ }^{8)}$ If the leaching of alkalies is due to the secondary hydration of volcanic glasses, the radiogenic argon residing in glass should be affected. Hence, the $\mathrm{K}$-Ar ages of these volcanic glasses may not be taken at their face values.

As shown in Fig. 2 and Fig. 3, there is the same tendency between $\mathrm{K} \cdot \mathrm{H}_{2} \mathrm{O}(+)$ and $\mathrm{Na}-\mathrm{H}_{2} \mathrm{O}(+)$ as those reported by Aramaki and Lipman. ${ }^{8)}$ The apparent age and $\mathrm{H}_{2} \mathrm{O}(+)$ plot in Fig. 4 shows that there is also a negative correlation between them. As potassium content is almost the same for each obsidian, the decrease of apparent age with $\mathrm{H}_{2} \mathrm{O}(+)$ may attributed to the radiogenic argon loss during the hydration. Hence, it is important to examine the $\mathrm{H}_{2} \mathrm{O}(+)$ content to estimate the reliability of the $\mathrm{K}$-Ar ages of obsidians. From Fig. 4, it can be pointed out that obsidian whose $\mathrm{H}_{2} \mathrm{O}(+)$ content is above $1 \%$ by weight is likely to lose some radiogenic argon. As the $\mathrm{H}_{2} \mathrm{O}(+)$ content of a fresh obsidian is usually below about $0.5 \%$, all the obsidians except $B$ should have suffered of hydration and the $\mathrm{K}$-Ar ages of these obsidians should not be taken at their face values. Because of the small $\mathrm{H}_{2} \mathrm{O}$ $(+)$ content (about $0.6 \%$ ) and its fresh appearance, however, the K-Ar age of obsidian $\mathrm{B}$ may be regarded reliable.

Rhyolite $\mathrm{E}$ contains comparatively

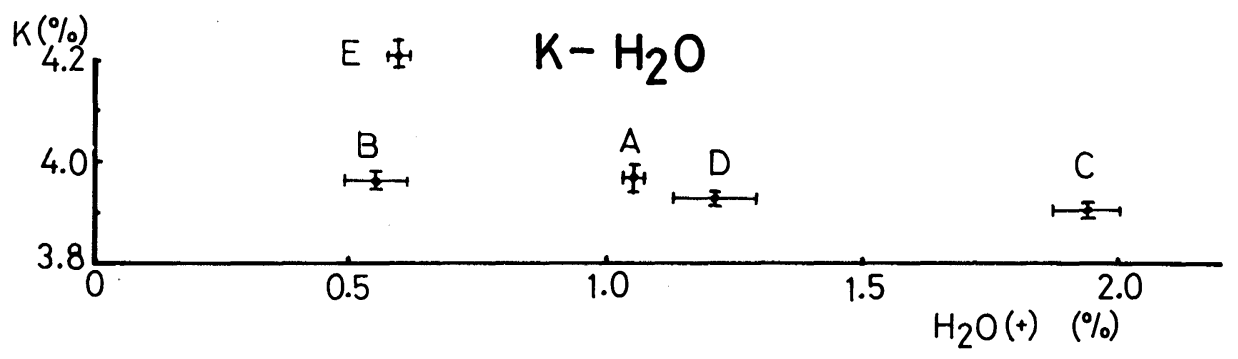

Fig. 2 The plot of $\mathrm{K}$ against $\mathrm{H}_{2} \mathrm{O}(+)$ of the obsidians and rhyolite 


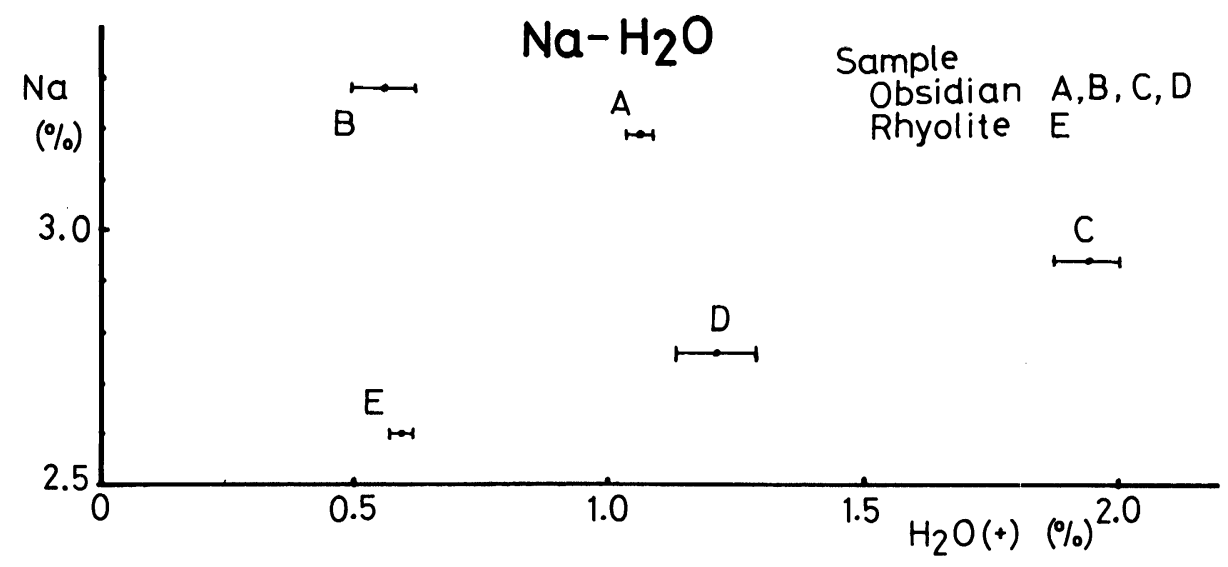

:6. 3 The plot of $\mathrm{Na}$ against $\mathrm{H}_{2} \mathrm{O}(+)$ of the obsidians and rhyolite

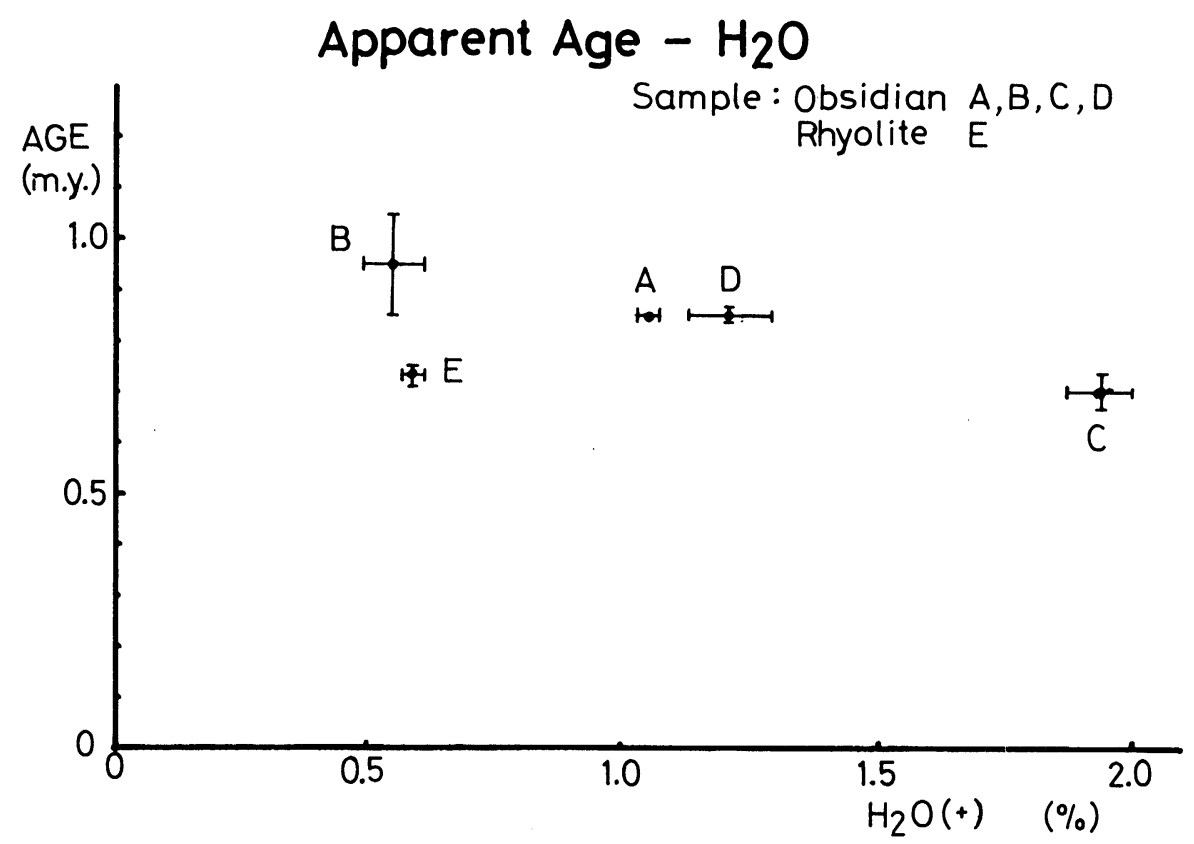

Fig. 4 The plot of apparent K-Ar age againșt $\mathrm{H}_{2} \mathrm{O}(+)$ of the obsidians and rhyolite

little $\mathrm{H}_{2} \mathrm{O}(+)$ of about $0.6 \%$ and the experimentally determined $\mathrm{K}-\mathrm{Ar}$ age is younger than that of obsidian. As both the rhyolite and the obsidian are considered to belong to a single geological formation, they should have the same age. This fact suggests that the argon retentivity of the obsidian is poorer than that of the obsidian. Therefore much precau- tion should be taken to evaluate the $\mathrm{K}$ Ar age of rhyolite.

The fact that the radiogenic argon loss is related clearly with the $\mathrm{H}_{2} \mathrm{O}(+)$ content for obsidian yields an evalution for the time duration of the hydration. If the hydration of obsidian occurred comparatively in short time soon after cooling from magmatic temperature, there 
would be little difference in the apparent ages. The difference between the oldest apparent age and the youngest one for obsidians, that is about $0.25 \mathrm{~m} . \mathrm{y}$. , indicates that some secondary hydration continues at least after $0.25 \mathrm{~m}$. y. or even up to the present since the formation of obsidian from the magma. This is a clear evidence of the secondary hy dration for the enrichment of $\mathrm{H}_{2} \mathrm{O}(+)$ content of some obsidians.

The mechanism of the leaching due to the hydration is not clear at present. Hydration is considered to destruct the silica chain structure of obsidians and causes more structure defects. As argon is very inactive with other ions, argon may be lost easily through these defects by diffusion. Therefore it is reasonable to suppose that the radiogenic argon content decreases with the degree of hydration of obsidians. On the other hand, sodium and potassium are more or less active with other ions. For the ion exchanges of these elements, the ionic radius may be one of the main factors, but the details are unknown. More study is necessary to solve the problem.

\section{Conclusions}

1) The radiogenic argon is lost from obsidian during its hydration and there is a clear correlation between the experimental $\mathrm{K} \cdot \mathrm{Ar}$ age and the $\mathrm{H}_{2} \mathrm{O}(+)$ content. With the increase of $\mathrm{H}_{2} \mathrm{O}(+)$ or the increasing degree of hydration, the K-Ar age becomes younger. Hence, in order to get a reliable $\mathrm{K}$-Ar age, it is an important provision to choose a fresh obsidian whose $\mathrm{H}_{2} \mathrm{O}(+)$ content is low, say below $0.5 \%$.

2) The argon retentivity of rhyolite studied here is poorer than that of obsidian.

3) The age of obsidian from $W$ ada Toge (pass) is about 0.9-1.1 m. y..**

4) Sodium is leached from obsidian during the hydration, whereas potassium contents are nearly the same for all obsidians studied here inspective of the difference in the degree of the ion exchanges.

In this study, only the effect of hydration of obsidian was studied. In order to use obsidian for K-Ar dating, the reliability must be studied further by comparing its age with other reliable samples. Furthermore, the existence of inherited argon in obsidian should also be studied. As a preliminary check, about 3 grammes of andesitic glass erupted in 1783 was used. The result shows that the ratio of ${ }^{40} \mathrm{Ar} /{ }^{36} \mathrm{Ar}$ for the extracted gas from the sample is 295.8. The value is almost the same one with that of atmospheric argon at present within experimetal error.

\section{Acknowled gemen ts}

The author expresses his sincere thanks to Dr. M. Ozima who gave him many kind suggestions in this work and read the manuscript giving him helpful comments. The author is grateful also to Drs. S. Aramaki and K. Sato for their useful suggestions. Dr. S. Aramaki kindly provided the sample of andesitic glass. Potassium and sodium was analysed by Mr. S. Zashu to whom the author is in-

** It is reported that $\mathrm{K}$ - Ar age shows $4 \mathrm{~m}$. y. for an obsidian at Wada Toge (pass) ${ }^{10}$ ) Further, fission track method gives the value of $0.5-0.7 \mathrm{~m} . \mathrm{y}$. for obsidians at Wada Toge (pass) !1) It is uncertain whether these differences in ages are due to the difference of samples or to other reasons. 


\section{Kaneoka}

debted very much.

\section{References}

1) J. F. Evernden and G. H. Curtis, Curr. Anthropol., 6, 343 (1965).

2 ) G. B. Dalrymple, Earth Planet. Sci. Letters, 3, 289 (1967).

3 ) J. H. Lipson, Bull. Geol. Soc. America, 69, 137 (1958).

4 ) M. Ozima, Personal communication

5 ) Y. Kawano, Report of Geol. Sur. Japan, No. 134 (1950).
6 ) M. Ozima, M.Goto, Y. Ogata and T.Suzuki, Mass Spectroscopy, 14, 177 (1966)

7 ) C. S. Ross and R. L. Smith, Amer. Mineralogist, 40, 1071 (1955).

8 ) S. Aramaki and P. Lipman, Proc. Japan. Acad., 41, 467 (1965).

9 ) S. Aramaki and H. Haramura, Jour. Geol. Soc. Japan, 72, 69 (1966). (in Japanese).

10) Y. Kawano and Y. Ueda, Sci. Rep, Tohoku Univ. Ser. III, 9, 99 (1964).

11) M. Shima, Personal communication. 